\title{
Arquivos Brasileiros de Ciências da Saúde: balanço 2007-2012
}

\section{Arquivos Brasileiros de Ciências da Saúde: balance 2007-2012}

\author{
Ricardo Peres do Souto
}

Editor Responsável - ricardo.souto@fmabc.br

Há cinco anos, foi publicado o primeiro fascículo do título Arquivos Brasileiros de Ciências da Saúde. A responsabilidade não era pequena, pois a tradição de três décadas do precursor Arquivos Médicos do $A B C$ precisava ser honrada. A expectativa por mudanças, no entanto, era ainda maior: ampliar o número de fascículos e de artigos publicados; conquistar interesse em todas as áreas das Ciências da Saúde; captar submissões de pesquisadores de todo o país. Uma a uma essas metas foram atingidas. Entre 2007 e 2012 , foram 130 artigos publicados em 15 fascículos, respeitando-se com rigor a nova periodicidade (quadrimestral). Nesse período, quase a metade dos artigos publicados (44\%) se originou de fora da Faculdade de Medicina do ABC, instituição de ensino e pesquisa onde se localiza a sede física da revista. Hoje, a $A B C S$ está classificada em dez áreas de avaliação do sistema Qualis da CAPES (http://qualis.capes.gov.br), incluindo Medicina, Saúde Coletiva, Enfermagem, Educação Física, Medicina Veterinária, Biotecnologia e Ciências Biológicas. Isso significa que pesquisadores das áreas listadas publicaram recentemente na $A B C S$ resultados de pesquisas realizadas em programas de pós-graduação stricto sensu recomendados pela CAPES. Ainda em relação ao Qualis, destaca-se a boa classificação da ABCS (estrato B3) nas áreas Enfermagem, Educação Física e Interdisciplinar.

Alguns outros marcos relevantes nesses últimos cinco anos incluem: uma coleção de depoimentos de destacados pesquisadores defendendo a importância da experimentação em animais de laboratórios (2008); um fascículo temático em Ortopedia (2010); a publicação do primeiro artigo com texto completo em inglês (2010); a parceria com o Congresso Internacional de Saúde da Criança e Adolescente (iniciada em 2011); a primeira nova indexação em base de dados internacional após vários anos - Index Copernicus (2012); e a divulgação eletrônica de todos os artigos em portal próprio de internet (http://www.nepas.org.br/abcs).

Tudo isso foi concretizado seguindo rigidamente a política editorial escolhida. Todas as submissões sofrem revisão duplo-cega por pares independentes, selecionados entre os pesquisadores ativos com experiência comprovada na metodologia e no contexto da pesquisa relatada. Devido ao seu amplo escopo, a $A B C S$ não tem lista fixa de revisores, que são identificados a cada submissão dentro da comunidade científica de todo o país por meio da Plataforma Lattes. Essa elevada exigência na análise das submissões resultou em taxa de reprovação de 38\% (período 2007-2012). Ao mesmo tempo, a eficiência no processamento dos artigos também evoluiu. Em 2012, a média de tempo entre a submissão e a aprovação foi de 4,5 meses (máximo 8 meses, mínimo 30 dias). É nítido o amadurecimento gradual da $A B C S$.

Para tanto, a revista conta com uma importante rede de colaboradores que cresceu consideravelmente no período. O corpo editorial atual inclui seis editores adjuntos, cada um com responsabilidades definidas. O conselho científico conta com 55 pesquisadores de alto prestígio distribuídos em todas as regiões do Brasil (e em outros países) e tem sido fundamental para divulgar o nome da revista e atrair novas submissões. Quadros técnicos do NEPAS, FMABC, FUABC e AcademicTI tem oferecido apoio qualificado e consistente. A Zeppelini Editorial tem sido importante parceira, emprestando sua experiência e garantindo excelência na apresentação da revista.

No atual contexto, novos desafios são necessários. Agora, é pertinente que a revista almeje uma identidade internacional. O primeiro passo dessa nova jornada é uma versão em inglês do título: ABCS Health Sciences. É a mesma revista, o nome em português permanece e o ISSN não muda, mas que deseja chegar mais longe. Em sequência, espera-se que outros anseios se tornem realidade: divulgação eletrônica de todos os artigos em plataforma especializada para revistas científicas, inclusão de Digital Object Identifier (DOI) para todos os artigos, indexação em novas bases de dados. Mas isso é assunto para os próximos balanços. 